\title{
A HISTÓRIA DO LADO DE LÁ: UMA LEITURA DE MEMÓRIAS DE ALDENHAM HOUSE
}

Giselle Larizzatti Agazzi

Universidade de São Paulo

É

este um romance, antes de tudo, antiimperialista.

Memórias de Aldenham House, último romance escrito por Antonio Callado e publicado em 1989, recompõe os tempos anteriores à chamada experiência democrática pela qual o Brasil passou entre 1945 e 1964. Em oposição a todos os outros oito romances do ficcionista e jornalista, sempre contemporâneos ao momento narrado, este é o único que remonta um passado mais longínquo, retrocedendo exatos 49 anos da história mundial.

A primeira narrativa de sucesso do autor, publicada em 1967, Quarup firma-se no conjunto de sua obra romanesca como uma espécie de livro protéico do qual as mais diversas possibilidades de leitura surgem, porque rascunha inúmeros veios que vão do confronto entre civilizações à crise existencial dos tipos representados. É também proteiforme, oferecendo-se aos romances subseqüentes como matéria primordial a ser trabalhada e desdobrada.

Desse texto utópico, Memórias de Aldenham House parece afirmar tal característica ao poder ser lido como um dos seus muitos reflexos, desdobrados em aspectos romanescos que envolvem o leitor numa teia de remorsos, culpas e impossibilidades e que fazem emergir a mais profunda melancolia. Nesse sentido, a narrativa compõe uma espécie de mito fundador às avessas. Como se o ficcionista, assumindo a maturidade que só os anos conferem para a análise acurada das Histórias, coletiva e pessoal, tentasse entender por quais motivos nem Brasil, nem América Latina, construíram sociedades livres e justas, emperrando o empenho das classes ilustradas 
que viam a literatura como um instrumento de humanização e de transformação das sociedades. É desse lugar que escreve Antonio Callado.

Desenvolvendo-se em torno do tema da construção da memória histórica, o escritor engendra aqui tantas outras suas obsessões: o universo feminino, o arcaico versus o moderno, a crítica aos governos autoritários, a problematização da construção da identidade individual e coletiva, as possibilidades e limites da Revolução Comunista, a justiça social. E define, em toque de despedida, o motivo fundamental que parece ser a linha de força dessa sua obra, a História vista a partir das catástrofes. Do ponto de vista da construção da memória, é este o aspecto a ser analisado.

Memórias é a história de um grupo de latino-americanos que busca exílio na Inglaterra nos anos de 1940 por causa da repressão política em seus países. $\mathrm{E}$ é um gênero hibridoํ. A narrativa apresenta-se como sendo memorialística sem entretanto ser apenas. Desenvolve estratégias próprias ao romance policial, mas não se caracteriza enquanto tal, porque termina por parodiar as categorias necessárias para a elaboração do gênero. Arrisca-se no romance realista, ao procurar recompor, através das particularidades dos personagens, o contexto histórico latino-americano, mas também não se firma nessas paragens, porque a matéria narrada só pode ser conhecida se o leitor procurá-la no que o livro procura ocultar. Assim, Memórias não é um romance realista, não é policial e muito menos biográfico. É uma narrativa ficcional que continua a desafiar o leitor moderno, exatamente por não se enquadrar em um único rótulo definidor e definitivo. Tal composição coloca o livro em um lugar que está entre muitos tipos, o que, desconcertando o público, exige que ele se desprenda de esquemas interpretativos, lançando-se à composição específica da obra, que se engendra à margem da tradição do romance brasileiro.

Se o narrador, para Walter Benjamin (1994), retira da experiência o que ele conta, o narrador de Memórias tenta compreender através do que ele escreve as experiências por que passou e que ouviu: Perseu Blake de Souza, o jornalista e comunista perseguido pela ditadura de Getúlio Vargas,

[Memórias] “Chegou mesmo a figurar como livro de memórias, nas listas dos mais vendidos e nem sempre mais lidos, a começar por quem deveria ler antes de anunciar, deixando-se enganar pelo título evidente de quem nem sequer o abriu” (In: LEITE, 2001, p. 34-50) 
registra suas memórias dos dias passados nos idos dos anos de 1940, na Inglaterra, junto a outros exilados políticos latino-americanos.

A esse foco narrativo, somam-se o narrador observador, o narrador onisciente, os narradores testemunhas, Elvira, a chilena de descendência irlandesa, tradutora de James Joyce, e Facundo, o paraguaio nacionalista, herói da Guerra do Chaco e pesquisador da Guerra de seu país contra a Tríplice Aliança, também jornalista e comunista. Porque compõe um quadro muito mais crítico e irônico do que o memorialista conseguiria, tal multiplicidade de pontos de vista permite ao leitor extrapolar os limites do olhar de Perseu, para Elvira, "frívolo" e "imaturo":

Sem dúvida encontrarei um ou outro brasileiro na BBC mas estarei sobretudo cercado de hispano-americanos, cucarachas. O diário terá a virtude simbólica de me manter a mim em minha especificidade brasileira, em nossa diferenciação. Por pouco que falemos nisto, pois parece arrogância, a verdade é a verdade, a História é a História, e, como dizia meu avô Souza, um homem é um homem e um gato é um gato. Há mais semelhança entre quaisquer dois países hispano-americanos - todos, sem exceção, caudilhescos e militaristas - do que entre um deles e o Brasil. Vargas, proveniente do sul espanholado, é, para nós, um desvio de rota, um enxerto hispânico ocasional. (p.42)

Embora ao paraguaio caiba o papel de protagonista, há outros personagens que em determinados momentos assumem essa função. Tal técnica de o escritor não construir seja um único protagonista, seja um único foco narrativo, movimenta as categorias romanescas e assegura a possibilidade de qualquer personagem adquirir importância no livro e a necessidade de o leitor conhecer o material narrado dos mais diversos pontos de vista.

Chegando ao exílio, Facundo e sua companheira inglesa Isobel, Perseu e Elvira se juntam a outros latinos e estrangeiros numa agência da BBC de Londres que se dedica à América Latina e que está sediada em Aldenham House, uma casa vitoriana cuja arquitetura tipicamente inglesa remete o paraguaio aos cenários de tantas das histórias de crime da literatura universal: "Aliás, lembrava Isobel, no exato momento em que, ao chegarem, entravam em Aldenham House, Facundo tinha perguntado, sério, a Moura Page: - Quedê o cadáver?” (p. 67). 
A atividade do grupo na casa, onde se encontra com os ingleses Moura Page e Herbert Baker, obedece a reuniões rotineiras para decidir a programação da rádio. Pela diversidade de interesses e de opiniões, pelas disputas e diferenças culturais, e principalmente pelos intensos embates travados entre Facundo e Baker, o clima é sempre tenso.

Embarcando nos discursos impacientes e provocativos do paraguaio, ainda no navio que os levava ao exílio, os latinos mergulham numa "expectativa de tragédia”, anunciada por Isobel e confirmada pelo suspense que o romance cria através de expedientes narrativos próprios aos livros policiais: a ambiência retesada desde as primeiras páginas diante do desafio que representa a partida do grupo para a Inglaterra pela condição de exilados dos que vão e pelos perigos a que a tribulação se expõe ao singrar o mar em plena Segunda Grande Guerra; a presença do tipo suspeito William Monygham, o inglês que trabalhava no Brasil e retorna à pátria por motivos de saúde, mas que, aos olhos de Isobel, é um policial disfarçado; o espaço hostil em que circulam os personagens e a apreensão e o nervosismo que caracterizam a interação entre eles; a construção de diversas imagens incompletas que se projetam como se ainda fossem ser continuadas em um momento posterior.

Tais elementos criam a ambiência da narrativa policial clássica que, pouco a pouco, vai se adensando diante da evidente incongruência entre a aparente frivolidade dos fatos narrados e o estado de espírito sobressaltado do grupo. No navio, há a expectativa de que a qualquer momento Monygham se revele como espião político, o Pardo seja atingido por uma bomba e Facundo dispare contra Perseu. Em Aldenham House, há o prolongamento e o agravamento das discussões entre Facundo e Herbert Baker e do comportamento estranho de ambos.

Aos indícios de que as memórias de Perseu perscrutam algo ainda a se revelar, ligam-se as observações sobre histórias policiais que o paraguaio, como um romancista, tece em tom grandiloqüente, ironizando o gosto dos britânicos por esse gênero e anunciando a trama que se desenvolverá contra ele mesmo:

- À medida, continuou Facundo, que a história se concatena, as situações se firmam, adensa-se o desenho, a trama se aviva, o suspense, em suma, para usar a palavra-chave, se instala e nos domina. Esse é o tricô, por excelência, que os ingleses inventaram para encher seu lazer impe- 
rial, seu ócio, seu tédio (...) Último lampejo de gênio da raça exausta, essas concatenadas histórias tecem mil caminhos num labirinto que só tem mesmo sua única e idiótica saída para lugar nenhum. (p. 163)

Quando surge o cadáver de Herbert Baker no lago de Aldenham House, o clímax aparentemente chega. Mas é aparente, porque não resolve o conflito narrativo a ser arrastado ainda até as últimas páginas do romance, quando Isobel morre, depois de Facundo ter sido assassinado pela polícia política paraguaia e de Perseu ter sido encarcerado mais uma vez pela mesma ditadura de Getúlio Vargas que o levara ao exílio anos antes.

De imediato, latinos e ingleses crêem o paraguaio ter sido o assassino de Baker muito mais pelo seu gênio irascível do que por alguma prova eficaz, já que, seguindo o modelo das boas histórias policiais, como admite Moura Page, todos na BBC teriam ao menos um bom motivo para matá-lo.

Facundo não se defende. Ao contrário, lança pistas contrárias, reforçando a tese de que seria ele mesmo o assassino. Nesse meio tempo, o temido policial paraguaio Emiliano Rivarola aporta na Inglaterra, disfarçado de embaixador, a fim de acompanhar de perto o julgamento do paraguaio exilado.

Já no tribunal, às exatas sessenta e seis páginas depois que o corpo de Baker fora encontrado, revela-se o que a polícia inglesa e Facundo sabiam há muito: "Mr Herbert Baker não sofreu, nos seus últimos momentos de vida, nenhuma violência, e, com muito mais razão, não foi vítima de qualquer injúria causada por qualquer espécie de arma; já estava morto, o coração parado, os pulmões imobilizados, ao ter a cabeça imersa no lago" (p.203).

A polícia inglesa insinua que Facundo emperrou as investigações, porque, além de negar-se a depor, teria arrastado o corpo de Baker do pavilhão de chá onde morrera para o lago onde fora encontrado. Desmoralizando o sistema legal britânico, o paraguaio evidencia a predisposição dos ingleses para imaginar grandes crimes em lugar dos acontecimentos cotidianos e triviais e a ver os estrangeiros contestadores como assassinos e a si mesmos como vítimas.

Para surpresa de Perseu, Facundo é condenado a tão somente pagar uma multa por toda sua encenação. $\mathrm{O}$ brasileiro consegue entender os motivos do Império a praticamente desprezar o comportamento do impávido Facundo em Paris, quando, depois do fim da guerra, Monygham lhe revela: 
- Não se pode mais tolerar hoje em dia, na seriedade da vida moderna, e sobretudo da guerra moderna, a entrada em cena dessa coragem de porre que é o heroísmo. Nos países civilizados tais intromissões não ocorrem mais, ou são aberrações, que acabam no consultório médico. Nos países atrasados o perigo continua latente, ameaçador. (p. 230-231)

Os britânicos zombam do heroísmo de Facundo. E também os paraguaios. O policial Emiliano Rivarola não tolera a volta e a resistência de Facundo à ditadura paraguaia e inventa argumentos para acusá-lo mais uma vez de ter matado Baker e atribuir-lhe a culpa pela morte de um outro inglês, John Cole. O torturador faz voltar à mídia uma velha história igualmente falsa de que o comunista enforcou seu companheiro de cela, quando ambos foram presos anos antes. A armação de Rivarola ganha as páginas dos jornais e da opinião pública e os fatos históricos se tornam mero exercício ficcional: "O espaço dado à foto era enorme mas o texto da notícia, impresso em negrito graúdo, era sucinto, pois "a Polícia não deve prejudicar investigações que estão sendo feitas em caráter de grande urgência”(p. 280). Sobre o romance policial, Marcelo Martins (2000) afirma que

no nível das estruturas narrativas policiais há um sujeito que transgride uma dada ordem, provocando uma ruptura na sociedade da qual participa, enquanto outro sujeito deve restabelecê-la de duas formas básicas, sancionando cognitiva e/ou pragmaticamente o transgressor. Esses dois sujeitos distintos, dotados dos papéis actanciais atribuídos pelas modalidades que regem o seu fazer e o seu ser serão, no nível das estruturas discursivas, actorializados, respectivamente, como criminoso e detetive.

Em Memórias, tal estruturação do romance policial é invertida, porque o assassino é o detetive, no caso, a polícia política, que comete o crime contra Facundo, contra a população e contra a História, ao condenar um homem inocente, divulgar falsas notícias e oficializar fatos ficctícios.

Diante da farsa, Facundo é ridicularizado.

Isobel é a única que verbaliza tal ironia que cerca a vítima da ditadura paraguaia, ao se negar a desmentir as versões criadas por Emiliano Rivarola mesmo com o pedido do seu amigo e advogado de Facundo Sir Cedric: 
Sir Cedric me contou, então, como, ao regressar Isobel do Paraguai, depois da morte de Facundo, tinha logo tratado de escrever a ela, que estava com a mãe, no Yorkshire, sugerindo-lhe as bases de um amplo trabalho a respeito de Facundo, contando corretamente sua história, mas a resposta de Isobel tinha sido surpreendente, na sua intransigência, quase hostilidade: com o consentimento dela não se moveria uma palha para cumprir um dever que competia exclusivamente aos paraguaios, que, por pouco que se amassem, “não podiam deixar de se amar em Facundo”. (p.303)

Depois de aconchegar seu companheiro, ajudando-o a suportar o pesadelo em que se tornara sua vida, Isobel desiste de lutar pela transformação da História latino-americana. Renega, pois, as possibilidades de mudança narradas por outra história que corre paralela à de Facundo na voz de Elvira, a de Finnegans Wake. Buscando incansavelmente traduzir para o espanhol a obra de James Joyce, Elvira atualiza a trajetória de Humphrey Chimpden Eawicker, taberneiro em Dublin, que remói o crime de que foi vítima e algoz, patinando na culpa e no remorso, dos quais enfim se liberta quando a narrativa aponta para o tempo mítico, continuamente repetido e renovado. Como afirma Lígia Chiappini: "Esse herói-anti-herói acaba morrendo mas renasce das cinzas em sucessivas metamorfoses. O tempo é cíclico. Tempo de resistência em tempo de modo irônico de ficção” (LEITE, 2001, p.34-35).

Em Memórias, esse tempo cíclico dialoga com o de Finnegans Wake. Mas para trabalhar em chave oposta. Porque o eterno retorno à situação original mimetiza a perpetuação da violência e da opressão na História do continente sul-americano e não a renovação utópica que, em Dublin, Humphrey experimenta.

Dialogando com um dos grandes ícones do modernismo, a obra de Callado ilumina a entrada problemática das nações latinas na modernidade, apropriando-se de um gênero, o dos policiais, “cujo apogeu literário se localizou no século XIX”, como nos lembra Flávio Aguiar (1997, p.101-1033).

Presos nos escombros das memórias pessoais e coletivas, os personagens de Callado não conseguem se libertar das engrenagens da História de que participam, materializadas nas ironias que o romance tece ao associar elementos dissonantes numa única cena ou persona: caso de Perseu, comunista brasileiro que não quer ser identificado com os outros latinos; ou de Facundo, antiimperialista com ares xenófobos, casado com a inglesa Isobel; 
ou da incapacidade de comunicação entre os latino-americanos lida nas freqüentes discussões entre o brasileiro e o paraguaio:

- Eu não sei se você (Perseu), como brasileiro, entende (...) o que significa ser paraguaio. Nós ficamos tão aleijados, tão deformados por aquela guerra que estamos até hoje gemendo e lambendo as feridas. Morreram todos os homens (...).

- Um país sofrido o seu, disse Perseu, vago, olhando o mar vazio. (p. 29)

Esses elementos em tensão ganham um certo tom melancólico, porque esvaziam antigos imaginários utópicos, como se lê quando o projeto unificador do continente latino-americano é escrachado nos constantes debates entre os próprios latinos e entre eles e os estrangeiros.

As perspectivas que se multiplicam na voz de Facundo retornam sempre a eventos traumáticos da História, os quais, não tendo sido superados, reatualizam-se continuamente em roupagens novas. Também as de Perseu, o qual faz de suas "lembranças descosidas" o espaço da melancolia dentro do exílio que cada personagem experimenta em si mesmo:

Prometi a Sir Cedric que, logo que caísse a ditadura no Paraguai, e no caso de estar eu solto na ocasião, iria ao cemitério de Assunção, para tornar, de alguma forma, mais explícito o túmulo de Facundo e Isobel Rodríguez. Sir Cedric me apertou a mão, fez um aceno, com o chapéu, ao coronel-comandante, e se retirou, enquanto eu iniciava, acompanhando de Josefo, o retorno à cela, onde escrevo tudo isso no Diário. Ou, melhor, onde encerro esta parte das minhas descosidas memóiras, colocando, aqui também, uma lápide, em homenagem a minha doce rival, Elvira, e aos companheiros de Aldenham House:

Zee End. (p. 306)

As sombras do passado vão se atualizando progressivamente até o retorno de Facundo e Perseu às suas respectivas pátrias, onde não conseguirão traçar novos destinos apesar de o tempo ter passado enquanto cumpriam o exílio. Indo ao encontro do que já se lhes havia sido predestinado antes da partida para a Inglaterra, a morte e a prisão, os personagens retornam mais uma vez à origem sem que isso signifique a modernidade conquistada pelo personagem de Joyce, ou seja, a liberdade da engrenagem das catástrofes históricas a que estão presos o paraguaio e o brasileiro. 
Ainda no navio, Facundo dá início às discussões, que se estenderão até a morte de Baker, a respeito da literatura e da cultura do Império Britânico. Ele acusa os ingleses de produzirem "uma avalanche de romances policiais” de péssima qualidade, porque não souberam aproveitar a "colossal acumulação primitiva de cultura” (p.16), fruto da espoliação das colônias, restando-lhes explorar a própria alma nacional, limitada, mesquinha e violenta, apesar de aparentemente grandiosa.

Ao ironizar a decadente produção literária da Inglaterra, Facundo desconstrói imagens tradicionais e desloca o centro cultural para o novo continente, a fim de provar sua hipótese de que o Império esconde os cadáveres que produz nos países colonizados. Entretanto, para o paraguaio, como nenhum crime é perfeito, a avalanche de títulos policiais constituem as pistas que, se bem montadas, provam a ação criminosa do imperialismo contra as colônias.

Facundo funda uma teoria crítica: investigar a mania dos britânicos por narrativas policiais é investigar a tendência daquele país de fazer do entretenimento uma maneira de disfarçar as suas recorrentes investidas violentas contra outras nações. E como toda expressão traz em si marcas definitivas do contexto que a gerou, os livros de Conan Doyle seriam o produto bruto da ação colonizadora dos ingleses, nascido da ausência de um outro contexto histórico, mais humanista, que poderia, como em outros tempos, ter gerado autores de genuínas "obras monumentais":

- Em termos marxistas a Inglaterra fez, no passado, uma colossal acumulação primitiva de cultura, mas já gastou quase tudo. (...)

- (...) E o que me diz da publicação de livros, Señor Rodríguez? Com a guerra, o papel de impressão ficou grosseiro, utilty paper, como dizem lá, mas os livros continuam a chegar ao povo numa verdadeira avalanche, uma inundação.

- Chegam, disse Facundo. Uma avalanche. Uma inundação. Mas de romances policiais. (...) Olhe, disse Facundo, quem entende de literatura inglesa, lá em casa, é minha mulher, aqui presente. Já ouvi dela, até dando aula particular, em nossa sala, que só dois irlandeses, veja bem irlandeses, criaram obras monumentais em inglês neste século, Bernard Shaw e James Joyce. Ah, ia me esquecendo, tem um poeta também, muito dos amores de Isobel, chamado Eliot, mas este é de uma colônia ainda mais distante que a Irlanda. (p.17) 
A imaginação doentia dos ingleses para escrever e consumir histórias policiais traduz, para Facundo, a relação que esse povo mantém com outros povos e o desejo de esconder o impulso violento que o caracteriza.

Como o paraguaio procura provar ao ser acusado de ter assassinado o inglês Hebert Barker, os métodos políticos do imperialismo inglês são os mesmos do romance policial.

Nesse sentido, Facundo fornece ao leitor o olhar crítico que deve ter se quiser compreender estas Memórias, ensinando-nos, num desdobramento metonímico e metalingüístico, a importância de descobrir-se nos métodos romanescos o que está se ocultando, o que está silenciado.

É dessa leitura atenta (exigida pelo paraguaio, também por Elvira, que, ao acusar Perseu de ser por demais preguiçoso para conseguir adentrar Finnegans Wake, envia seu recado ao leitor das memórias narradas) que, num lapso, torna-se possível perceber esse texto híbrido como algo mais do que a paródia do clássico romance policial inglês.

Se o leitor se der ao trabalho de debruçar-se por alguns Conan Doyle, livros de referência de que se utiliza Facundo para provar sua teoria, logo perceberá que há uma clivagem entre tais textos e o tipo policial aqui parodiado, porque a narrativa traz marcas de uma certa modernização da maneira de pensar o mundo advinda da contribuição da obra de Sigmund Freud para a cultura universal. É só através das teorias sobre o inconsciente, a repressão, os atos falhos, que podemos entender o raciocínio de Facundo sobre o Império (porque se baseia na noção de atos falhos, já que o romance policial é visto pelo paraguaio como uma das evidências da tendência violenta do Império), a ação de Rivarola torturando psicologicamente o paraguaio, a intertextualidade estabelecida com Finnegans Wake, a problematização da identidade nacional de Facundo e de Perseu.

Nessa falta de ajuste entre as marcas textuais, Memórias reivindica o diálogo com outras narrativas policiais, as que se sucederam às originais, e que são bem representadas pela herdeira do gênero, nas palavras de Flávio Aguiar, a "conservatriz Agatha Christie":

O detetive é o anjo do bem; o assassino-mor é o gênio do mal; como contrários eles se anulam, isto é, transformam-se na mesma substância. Tal processo de fissão, quase nuclear para o mundo maniqueísta 
dos romances de detetive, exige um dispêndio enorme de energia - quer dizer -, um verdadeiro rocambole da arte de narrar. Para o século XIX de Sherlock chegaram as paisagens grandiosas. Para o Hercule Poirot ${ }^{2}$ de hoje, que a trancos e barrancos perseguiu ser o sucessor daquele Sherlock, é preciso um pouco mais. (AGUIAR, 1997, p.101-103)

Esse "pouco mais" de que fala Flávio Aguiar é, como afirma linhas adiante, "algum...conhecimento de psicologia": "Essa técnica, no entanto, o define apenas como um inovador muito relativo no terreno da ficção policial. Pode-se até vê-lo, na verdade, como um confirmador das regras mais sagradas da novela de mistério. Essa, quem sabe, seria a sua real "inovação”.

Em Memórias, há nos personagens esse "conhecimento" a mais a que se refere Aguiar. E há, também, os elementos clássicos do romance policial do século XIX. O encontro das duas vertentes faz os dois tempos em que foram geradas coexistirem, definindo um outro tempo, esse, o do escritor.

É o autor que, despertando certo estranhamento no leitor, provoca a reflexão sobre as conseqüências desse texto que, para além do entre-lugar ocupado pela narrativa híbrida, coloca-se também num entre-tempo: forjando a ambiência policial entre um e outro modelo policial, Memórias faz reverberar o novo-velho romance policial inglês e traz em si a imagem daquele detetive cuja "real inovação" é confirmar as "regras mais sagradas da novela de mistérios".

Essa é, enfim, a metáfora a ser destrinchada com a ajuda da teoria de Facundo sobre os imperialistas agirem segundo os métodos das novelas policiais.

Antonio Callado, afirmando o livro segundo um olhar retrospectivo, ilumina mais uma artimanha do Império, o qual, a despeito das reais mudanças no contexto histórico internacional depois da Segunda Grande Guerra, mantém o bastão que rege a História, agora, com "algum conhecimento de psicologia”, perpetuando as mais arcaicas formas de opressão e de violência ao ensinarem às classes dominantes dos países colonizados a também conduzirem a História de maneira autoritária. É o que Emiliano Rivarola representa.

2 Hercule Poirot é o detetive do romance resenhado por Flávio Aguiar (CHRISTIE, Agatha. Cai o pano - o último caso de H. Poirot. Rio de Janeiro: Artenova, 1975). 
Esse é o crime mais violento e o mais oculto que é desvelado pelas estratagemas narrativas.

Mas isso só se depreende do silêncio que a obra, por arte do engenho, impõe. E Antonio Callado, ao parodiar o romance clássico policial, numa última investida utópica, parece apostar que o leitor dessas memórias descobrirá o que se nega a tornar-se evidente.

A pergunta de Facundo “- Como é que um paraguaio vai escrever um romance policial?”, lançada a seu advogado Sir Cedric, em tom sardônico, fica latente ao longo de todo o livro. Não é Sir Cedric, entretanto, que formula a resposta. Mas na própria construção de Perseu e de Facundo, os quais, presos a uma memória histórica composta por episódios violentos (o cárcere, os assassinatos, o exílio, as perdas sentimentais), fazem emergir uma versão da História contada a partir das violências, das catástrofes e das impossibilidades de superação das desigualdades econômicas, sociais e cultuais. Ao contrário da versão dos colonizadores, contada a partir de progressos tecnológicos e riquezas acumuladas.

Nesse sentido, enquanto os ingleses criam histórias policiais do ponto de vista dos vencedores, aos latinos resta criarem-nas do ponto de vista do que se lhes opõe, o dos vencidos.

Surge, por isso, a paródia, esta, sim, forma por excelência dos latinos, que foram obrigados a ler o mundo através das lentes dos imperialistas, mesmo sendo os colonizados. Só de dentro dessa perspectiva irônica que caracteriza a História dos trópicos é que se torna possível escrever o romance policial: os vencidos apropriarem-se dos métodos estrangeiros para contar sua História, mas não podem livrar-se da evidência de estarem do lado de lá.

\section{BIBLIOGRAFIA}

AGUIAR, Flávio Wolf de. "Morte in Glória”. In: AGUIAR, Flávio Wolf de. A palavra no purgatório. Literatura e Cultura nos anos 70. São Paulo: Boitempo, 1997.

BENJAMIN, Walter. Magia e Técnica, arte e política: ensaios sobre literatura e história da cultura. São Paulo: Brasiliense, 1994.

CALlADO, Antonio. Quarup. Rio de Janeiro: Civilização Brasileira, 1967. Memórias de Aldenham House. Rio de Janeiro: Nova Fronteira, 1989. 
LEITE, Lígia Chiappini. "A Casa Assassinada ou a Inglaterra vista da AmericaLatindia”. In: AGUIAR, Flávio e VANCONCELOS, Sandra Guardini T. Imagens da Europa na Literatura Brasileira. Cadernos Comarca, São Paulo: Humanitas, FFLCH, 2001.

MARTINS, Marcelo Machado. Narrativa policial (uma abordagem semiótica). Dissertação de mestrado, Universidade de São Paulo, 2000. 